\title{
Effects of Selected Dietary Secondary Metabolites on Reactive Oxygen Species Production Caused by Iron(II) Autoxidation
}

\author{
Vladimir Chobot $^{1, *}$, Franz Hadacek ${ }^{2}$ and Lenka Kubicova ${ }^{1}$
}

1 Division of Molecular Systems Biology, Department of Ecogenomics and Systems Biology, Faculty of Life Sciences, University of Vienna, Althanstrasse 14, A-1090 Vienna, Austria; E-Mail: lenka.kubicova@univie.ac.at

2 Department of Plant Biochemistry, Albrecht-von-Haller Institut, Georg-August-Universität Göttingen, Justus-von-Liebig-Weg 11, D-37077 Göttingen, Germany;

E-Mail: franz.hadacek@biologie.uni-goettingen.de

* Author to whom correspondence should be addressed; E-Mail: vladimir.chobot@univie.ac.at; Tel.: +43-1-4277-76551; Fax: +43-1-4277-9542.

External Editor: Maurizio Battino

Received: 11 August 2014; in revised form: 22 November 2014 / Accepted: 24 November 2014 / Published: 1 December 2014

\begin{abstract}
Iron is an essential co-factor for many enzymes that catalyze electron transfer reactions. It is well known that so-called "poorly liganded" iron can increase ROS concentrations and trigger oxidative stress that is capable of initiating apoptosis. Conversely, controlled ROS production has been recognized as an integral part of cellular signaling. Elevated ROS concentrations are associated with aging, inflammatory and degenerative diseases. Anti-aging properties have been attributed especially to antioxidant phenolic plant metabolites that represent food additives in our diet. Consequently, this study explores the effects of flavonoids (quercetin and rutin), several phenolic acids (caffeic, chlorogenic, and protocatechuic acid), and the alkaloid caffeine on iron(II) autoxidation and ROS production in comparison to the standard antioxidants ascorbic acid and Trolox. The iron(II) autoxidation assay was carried out in $\mathrm{pH} 6.0$ (plant apoplast and inflamed human tissue) and 7.4 (cell cytoplasm and human blood plasma). The obtained results accentuate phenolic acids as the more specific antioxidants compared to ascorbic acid and Trolox. Flavonoid redox chemistry depends more on the chemical milieu, specifically on $\mathrm{pH}$. In vivo, the presence of iron cannot be ruled out and "wrongly" or "poorly" complexed iron has been pointed out as causative agent of various age-related diseases.
\end{abstract}


Keywords: iron(II) autoxidation; dietary antioxidants; polyphenols; superoxide; hydroxyl radical; free radicals; oxidative stress; aging; inflammation; chronic diseases

\section{Introduction}

Iron ions catalyze various electron transfer reactions in plant and animal cells, mostly as enzymatic cofactors, but also in coordination complexes with low-molecular-weight metabolites or drugs. Uncontrolled one-electron transfers may lead to the production of reactive oxygen species (ROS), which are required for maintaining a redox homeodynamic equilibrium and signaling in low concentrations but can cause oxidative stress in higher concentrations [1-4]. High ROS concentrations have been identified as key factors in development of many degenerative processes contributing to aging $[3,5,6]$. The most dangerous ROS is the highly reactive hydroxyl radical $\left({ }^{\circ} \mathrm{OH}\right)$ which is able to oxidize practically every molecule in the cell [7,8]. Hydroxyl radical arises by one electron reduction of hydrogen peroxide (Equation (1)):

$$
\mathrm{H}_{2} \mathrm{O}_{2}+\mathrm{Fe}^{\mathrm{II}} \rightarrow{ }^{-} \mathrm{OH}+{ }^{\cdot} \mathrm{OH}+\mathrm{Fe}^{\mathrm{III}}
$$

Reaction (1) is known as the Fenton reaction and iron(II) is an initiator of this reaction. Hydrogen peroxide can arise by a spontaneous or enzymatically catalyzed dismutation of superoxide anion radical $\left(\mathrm{O}_{2}{ }^{\circ-}\right)$ (Equation (2)). The superoxide anion radical is a product of iron(II) autoxidation (Equation (3)) or accidental one-electron transfers in mitochondria or chloroplasts [9]:

$$
\begin{gathered}
2 \mathrm{O}_{2}^{\cdot-}+2 \mathrm{H}^{+} \rightarrow \mathrm{H}_{2} \mathrm{O}_{2}+\mathrm{O}_{2} \\
\mathrm{O}_{2}+\mathrm{Fe}^{\mathrm{II}} \rightarrow \mathrm{O}_{2}{ }^{--}+\mathrm{Fe}^{\mathrm{III}}
\end{gathered}
$$

The stability of iron oxidation states depends on the $\mathrm{pH}$ of solution. Iron(II) is more stable in acidic solutions than in the alkaline ones where it becomes more easily oxidizable to iron(III) in the presence of molecular oxygen [10]. Biologically relevant $\mathrm{pH}$ values are 7.4 (cell cytoplasm and human blood plasma) and 6.0 (plant apoplast and inflamed human tissue) [11-13]. A pH lower than 6.0 can occur in special compartments and organs such as plant vacuoles, lysosomes or the human stomach [13-15].

Because of the presence of various reducing agents such as ascorbic acid, glutathione or NAD $(\mathrm{P}) \mathrm{H}$, iron occurs in cells mainly in its divalent state [16]. Redox properties of iron and its ability to produce ROS depend on the types of ligands which form complexes with iron. The ligands containing oxygen groups such as phenolic or carboxyl groups decrease the iron redox potential. Ligands with nitrogen or sulphur containing groups, such as for example in amines, the heterocycles imidazole and pyridine, and the thiol group of cysteine, by contrast, increase the redox potential of iron $[10,17,18]$. In addition, iron complexes with phenols, especially flavonoids, can catalyze superoxide anion dismutation similarly as superoxide dismutase (SOD) and enhance the rate of the redox reaction cascades, resulting in the Fenton reaction $[19,20]$.

Plant polyphenols and some alkaloids such as caffeine occur ubiquitously in human diet. Daily uptake of these compounds may be in order of dozens or hundreds of milligrams because their concentrations in food plants can be very high [16,21-23], depending on the growth conditions [24-26]. The effects of plant metabolites and dietary supplements on human health have been a subject of discussions for a 
long time [4,27-30]. For example, the purine alkaloid caffeine is a constituent of very popular beverages, tea, coffee, and energy drinks. Recently, caffeine has been a topic of debates about beneficial effects of its chronic consumption on the withdrawing cognitive functions associated with aging [31]. Although the function of flavonoids, phenolic acids and alkaloids in the plant is still far from being fully understood, these compounds possessing redox and/or iron chelating properties have been attracting attention for possible preventing the onset of several degenerative diseases connected with aging [16,32-36].

The iron(II) autoxidation assay explores ROS formation dynamics connected with reduction of molecular oxygen that diffuses into aqueous reaction mixtures [37]. In the first step, molecular oxygen is reduced by iron(II) to superoxide anion radical (Equation (3)). The final product of a complex reaction cascade is the highly oxidative hydroxyl radical that attacks the detection molecule 2-deoxy-D-ribose. Its decomposition products can be quantified photometricaly after reaction with 2-thiobarbituric acid as thiobarbituric acid reactive species (TBARS). The added test compound can accelerate or slow down the rate of the 2-deoxy-D-ribose degradation by ROS scavenging and production and/or by acting as ligands in iron coordination complexes. The redox chemical properties of coordination complexes cannot be predicted easily because they depend both on the spin rates of the valence electrons and on steric factors, which affects the redox potentials of both central atom and ligands $[10,17,18]$. Many well-known antioxidants may show a pro-oxidant activity, either by directly reducing molecular oxygen to superoxide anion radical or by affecting $\mathrm{Fe}(\mathrm{II}) / \mathrm{Fe}(\mathrm{III})$ redox cycling [18,38-40].

This paper explores the redox chemistry of selected substances with diverse structures, flavonoids, quercetin and rutin, phenolic acids, caffeic, chlorogenic, and protocatechuic acid, and the alkaloid caffeine, in comparision to standard antioxidants, ascorbic acid and a water soluble tocopherol analogue, Trolox (Figure 1), with a specific focus on iron(II) autoxidation and ROS formation in aqueous reaction mixtures at two different physiologically relevant $\mathrm{pH}$ values, 7.4 and 6.0.

Figure 1. Structures of the tested compounds.
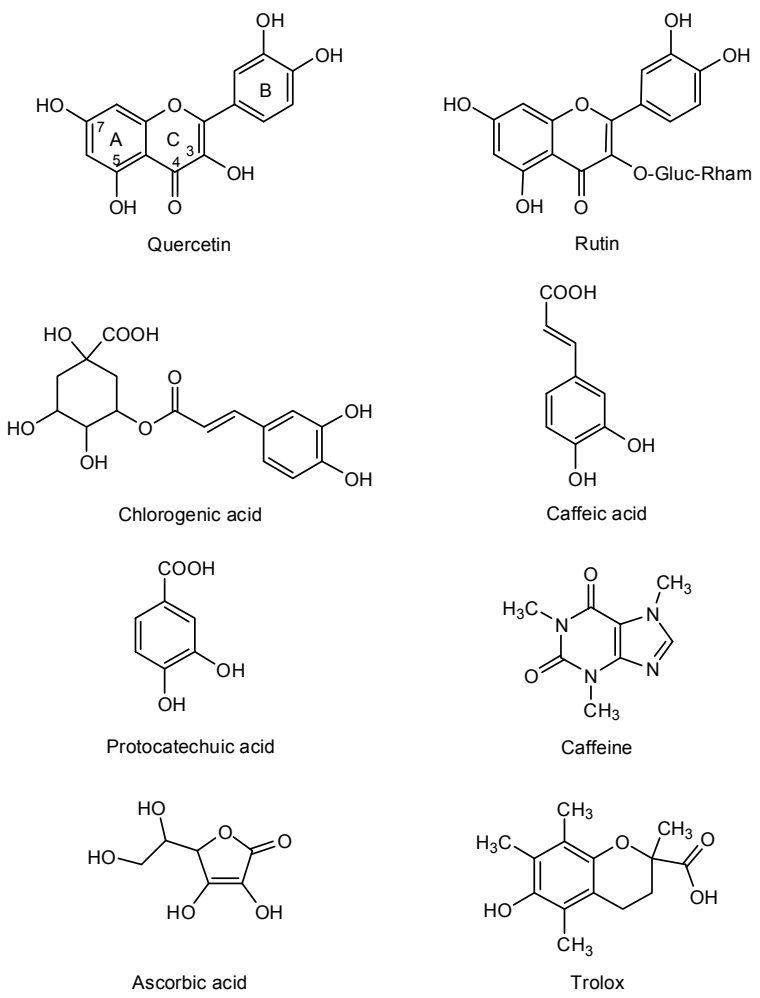


\section{Results and Discussion}

The assay revealed interesting differences among the tested compounds in terms of their effects on iron(II) autoxidation and ROS-triggered 2-deoxy-D-ribose degradation (Figure 2). The pH effects were pronounced in some cases and negligible in others.

Figure 2. ROS generation in the Fe(II) autoxidation assay. Graphs (A)-(H) show activities of the tested compounds (A, quercetin; B, rutin; C, chlorogenic acid, D, caffeic acid; E, protocatechuic acid; F, caffeine; G, ascorbic acid; H, Trolox) in the assay. ROS were quantified as thiobarbituric acid reactive species (TBARS) arising from oxidative degradation of 2-deoxy-D-ribose. The results are presented as TBARS levels relative to the control $(100 \%=$ TBARS of the control reaction mixture without test compound $)$. The final concentration of $\mathrm{Fe}(\mathrm{II})$ in the reaction mixture was $10 \mu \mathrm{M}$. Error bars indicate standard deviation of three replicates; letters $(\mathrm{a}-\mathrm{i})$ indicate different levels of significance $(95 \%$ Duncan), for details see Experimental Section.
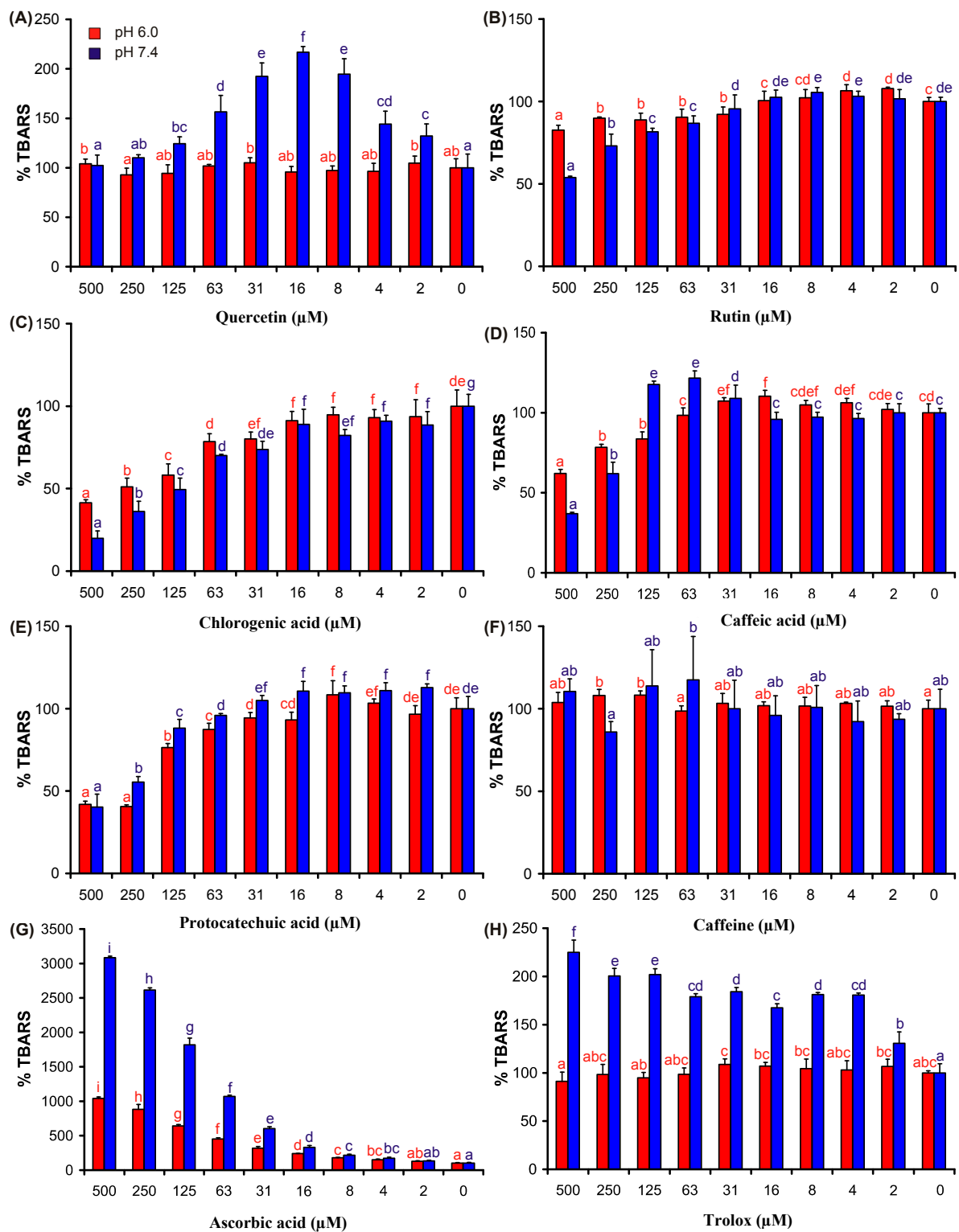
The flavonoid quercetin was pro-oxidant in the concentration range $2-125 \mu \mathrm{M}$ in pH 7.4 (Figure $2 \mathrm{~A}$ ). In the higher concentration range, 250-500 $\mu \mathrm{M}$, quercetin's ROS scavenging properties became more pronounced than its pro-oxidant activity. The dose-response curve showed an inverted U-shape form. At $\mathrm{pH}$ 6.0, however, the anti- and pro-oxidant activities disappeared. A possible reason for this effect can be a decreased dissociation of phenolic hydroxyl groups. Oxidation of phenolic hydroxyl groups depends on their dissociation and is more difficult to occur in acidic $\mathrm{pH}$ [41]. By contrast, rutin behaved as an antioxidant in both pHs (Figure 2B), the $o$-dihydroxyl group arrangement of ring $\mathrm{B}$ being most probably responsible. This points to the contribution of the non-substituted 3-hydroxyl group on ring $\mathrm{C}$ to the pro-oxidant activity of quercetin [42-44]. The pro-oxidant properties of quercetin at $\mathrm{pH} 7.4$ depend on ability of quercetin and its semiquinone to reduce molecular oxygen to superoxide anion radical and hydrogen peroxide [38,45]. Quercetin is oxidized to semiquinone by superoxide anion radical, a reaction product of iron(II) autoxidation. Semiquinones of flavonoids with $o$-dihydroxyl or trihydroxyl groups are known as potent reducing agents which can reduce molecular oxygen to superoxide anion radical $[38,45]$. Superoxide anion radical dismutates or can be reduced to hydrogen peroxide by another quercetin molecule. These processes lead to a quick formation of hydrogen peroxide which enters in the Fenton reaction.

Both flavonoids are able to form coordination complexes with iron which can affect the studied 2-deoxy-D-ribose degradation in a multi-faceted fashion. The ability of complex formation of flavonoids with metals such as iron depends on the number of hydroxyl groups and their arrangement in the flavonoid molecule [46-49]. For example, flavonoids with $o$-dihydroxyl group on ring B as rutin and quercetin were identified as efficient iron chelators. The hydroxyl groups at positions 3 of ring $\mathrm{C}$ or 5 of ring $\mathrm{A}$ and 4-keto group of ring $\mathrm{C}$ also represent good coordination sites; the efficiency of the latter, however, is low in acidic environment [47,50]. Ligands with oxygen coordination atoms such as flavonoids do not prevent iron(II) autoxidation but stabilize iron in trivalent oxidation state by shifting the iron redox potential into the cathodic direction [10,16,17]. As a result of this effect, iron(II) is more easily oxidized to iron(III) but iron(III) back reduction to iron(II) is more difficult [17].

Perron et al. suggest that the polyphenols increasing the rate of iron(II) autoxidation protect DNA against oxidative damage. The authors propose a higher redox stability of iron(III) in iron(III)-flavonoid coordination complexes [46].

In contrast to the tested flavonoids, all phenolic acids, caffeic, chlorogenic and protocatechuic acid, proved to be efficient antioxidants in both tested $\mathrm{pH}$ environments (Figure $2 \mathrm{C}-\mathrm{E}$ ). Their activity was slightly more pronounced at the alkaline $\mathrm{pH}$ than in the acidic reaction mixture due to better dissociation and increased electron density of the carboxylate. Chlorogenic acid was the most active antioxidant of all tested compounds. The effect of caffeic acid was comparable to the activity of protocatechuic acid. However, this contradicts reports suggesting that ROS scavenging activity of hydroxycinnamic acids is higher than that of corresponding hydroxybenzoic acids because of the extended electron delocalization [44,51] and possible addition of hydroxyl radicals to the vinyl group of the cinnamic acid derivatives [52,53]. This points to the fact that not only ROS scavenging, but also inhibition of iron catalytic ability and iron redox cycling in coordination complexes contribute to the antioxidant properties of phenolic acids [16]. Acids with $o$-dihydroxyl groups have been pointed out as potent iron chelators, chlorogenic acid > caffeic acid > protocatechuic acid [54], by forming stable coordination complexes with trivalent iron. Caffeic and protocatechuic acids efficiently promoted iron(II) autoxidation 
in the ferrozine assay that was carried out in HEPES buffer [55]. Conversely, other reports suggested that chlorogenic and caffeic acid were able to reduce iron(III) back to reactive iron(II) in the iron-acid complexes by one electron intermolecular transfer [56]. These reactions were carried out in acidic environment where iron(III) is more reactive than in neutral or alkaline solutions [10]. At pH 7.4, Chvatalova et al. reported only slow reduction of iron(III) in chlorogenic or caffeic acid complexes [55]. None of the tested phenolic acids showed detectable pro-oxidant activity in the iron(II) autoxidation assay. Consequently, our results concur with those reported by Chvatalova et al. [55].

The alkaloid caffeine showed no antioxidant activity in the range of the tested concentrations (Figure 2F), although caffeine is able to form adducts with hydroxyl radical, predominantly at the site C8 [57]. However, caffeine has been identified as a bad scavenger of hydroperoxyl radical, a protonated form of superoxide anion radical [57,58], and as a weak iron chelating agent [59]. The lack of protective effects of caffeine against oxidative degradation of 2-deoxy-D-ribose can be explained by lower caffeine reactivity towards hydroxyl radical compared to 2-deoxy-D-ribose as well as by insufficient inhibition of iron catalytic properties by iron-caffeine coordination complexes.

The standard antioxidants, ascorbic acid and Trolox, did not prevent iron(II) autoxidation and ROS formation in both of the tested $\mathrm{pH}$ reaction conditions (Figure 2G,H). They apparently increased TBARS concentrations in the reaction solutions of $\mathrm{pH}$ 7.4. The evident pro-oxidant activities suggest a significant promotion of iron(II)/iron(III) redox cycling if iron is liganded by ascorbic acid or Trolox $[18,60]$. In contrast, ascorbic acid and Trolox showed antioxidant activity in other assays using various hydrophilic and lipophilic detection molecules [61]. It can be explained by different reaction rates of ROS with 2-deoxy-D-ribose compared to other detection molecules [62]. In the acidic reaction solutions, ascorbic acid was highly pro-oxidant whereas Trolox showed no significant activity. Our results agree with reported pro-oxidant effects of ascorbate in cancer chemotherapy [63].

\section{Experimental Section}

\subsection{Chemicals}

All chemicals used were purchased from Sigma-Aldrich (Schnelldorf, Germany). Water used was of Milli-Q quality.

\subsection{Fe(II) Autoxidation Assay}

The sample was dissolved in aqueous $\mathrm{KH}_{2} \mathrm{PO}_{4} / \mathrm{KOH}$ buffer solution $(30 \mathrm{mM}, \mathrm{pH} 7.4)$ and diluted serially; to this solution $(125 \mu \mathrm{L})$, a $52 \mathrm{mM}$ 2-deoxy-D-ribose solution $(25 \mu \mathrm{L})$ in the same buffer system, the buffer $(50 \mu \mathrm{L})$, and degassed aqueous $\mathrm{FeSO}_{4}$ solution $(50 \mu \mathrm{L}, 50 \mu \mathrm{M})$ were added. The final concentrations of the tested compounds were 2-500 $\mu \mathrm{M}$. Blanks contained the full reaction mixtures except for 2-deoxy-D-ribose. Standard $1.5 \mathrm{~mL}$ sample vials (La-Pha-Pack, Werner Reifferscheidt $\mathrm{GmbH}$, Langerwehe, Germany) were used as reaction vials. The mixture was incubated at $27{ }^{\circ} \mathrm{C}$ for $16 \mathrm{~h}$. Thereafter, $250 \mu \mathrm{L}$ of $1.0 \%$ thiobarbituric acid dissolved in $3 \%$ trichloroacetic acid (w/v) was added to each vial to detect TBARS. The vials were heated in a water bath at $80{ }^{\circ} \mathrm{C}$ for $30 \mathrm{~min}$. The reaction was stopped by transferring the vials into an ice water bath for $3 \mathrm{~min}$. To extract the TBARS, $600 \mu \mathrm{L}$ of 1-butanol was added, and the mixture was rigorously vortexed. The butanol layers of the 
vials, each $350 \mu \mathrm{L}$, were pipetted into flat bottomed 96 well plates (Greiner, Kremsmünster, Austria), and the absorbance was determined with a microplate reader (Tecan Infinite M200, Männedorf, Switzerland) at $532 \mathrm{~nm}$. Experiments were performed in triplicate. Reaction mixtures lacking the test compound served as the positive control (100\% TBARS). The phosphate buffer and water, which were used as solvents for the tested substances or $\mathrm{FeSO}_{4}$, were degassed by argon for $10 \mathrm{~min}$ at least. The assay was performed in aqueous solutions and phosphate buffer because organic buffers and solvents react with hydroxyl radicals [64].

\subsection{Statistical Analysis}

Statgraphics Centurion XVI (Statistical Graphics Corp., Rockville, MD, USA) was used to perform analyses of variance (ANOVA) employing 95\% Duncan's multiple range post hoc test.

\section{Conclusions}

In oxidative stress conditions, iron may be released from its coordination complexes with proteins or other ligands and can catalyze further production of ROS. The in vitro results presented here suggest that secondary plant metabolites, for example phenolic acids, possess considerable potential to protect molecular cell structures against the oxidative stress even at lower $\mathrm{pH}$ which accompanies inflammation processes often associated with degenerative diseases and aging. At cytosolic $\mathrm{pH}$, plant metabolites may increase ROS concentration by reducing molecular oxygen to ROS thereby affecting the rates of chemical reactions that are involved in iron redox cycling. The final activity depends on ratio between pro-oxidant and antioxidant processes. Generally, as the presented results demonstrate, reducing activity does not always correlate with capacity to inhibit oxidation [65]. A good example is ascorbic acid, for which the strong pro-oxidative effect that was evident in the assay concurs with its application in cancer chemotherapy. Redox active plant metabolites can contribute to maintaining the redox homeodynamic equilibrium in the cells $[4,8,66]$. Redox homeodynamic equlibrium implies that certain levels of ROS and oxidative products of some biomolecules such as lipids have to be present as signal molecules for regulation of metabolism [4]. Dietary redox active metabolites have thus potential to exert health-beneficial effects in certain patients, but also none or even detrimental ones in others. The reason is the complexity of involved chemistry revealed by the assay that was performed for this study.

\section{Acknowledgments}

This research was supported by the Austrian Science Fund (FWF), grant P24630-B21.

\section{Author Contributions}

Conception, design and manuscript preparation: V.C., L.K. and F.H.; data collection and analysis: V.C. and L.K. All authors read and approved the final manuscript.

\section{Conflicts of Interest}

The authors declare no conflict of interest. 


\section{References}

1. Droge, W. Free radicals in the physiological control of cell function. Physiol. Rev. 2002, 82, 47-95.

2. Foyer, C.H.; Noctor, G. Redox homeostasis and antioxidant signaling: A metabolic interface between stress perception and physiological responses. Plant Cell 2005, 17, 1866-1875.

3. Graves, D.B. The emerging role of reactive oxygen and nitrogen species in redox biology and some implications for plasma applications to medicine and biology. J. Phys. D Appl. Phys. 2012, 45, doi:10.1088/0022-3727/45/26/263001.

4. Niki, E. Do antioxidants impair signaling by reactive oxygen species and lipid oxidation products? FEBS Lett. 2012, 586, 3767-3770.

5. Valko, M.; Leibfritz, D.; Moncol, J.; Cronin, M.T.D.; Mazur, M.; Telser, J. Free radicals and antioxidants in normal physiological functions and human disease. Int. J. Biochem. Cell Biol. 2007, 39, 44-84.

6. El Assar, M.; Angulo, J.; Rodriguez-Manas, L. Oxidative stress and vascular inflammation in aging. Free Radic. Biol. Med. 2013, 65, 380-401.

7. Halliwell, B.; Aeschbach, R.; Loliger, J.; Aruoma, O.I. The characterization of antioxidants. Food Chem. Toxicol. 1995, 33, 601-617.

8. Hadacek, F.; Bachmann, G.; Engelmeier, D.; Chobot, V. Hormesis and a chemical raison d'être for secondary plant metabolites. Dose-Response 2011, 9, 79-116.

9. Halliwell, B. Reactive species and antioxidants. Redox biology is a fundamental theme of aerobic life. Plant Physiol. 2006, 141, 312-322.

10. Kosman, D.J. Iron metabolism in aerobes: Managing ferric iron hydrolysis and ferrous iron autoxidation. Coord. Chem. Rev. 2013, 257, 210-217.

11. Felle, H.H. pH: Signal and messenger in plant cells. Plant Biol. 2001, 3, 577-591.

12. Okajima, F. Regulation of inflammation by extracellular acidification and proton-sensing GPCRs. Cell Signal. 2013, 25, 2263-2271.

13. Martiniere, A.; Desbrosses, G.; Sentenac, H.; Paris, N. Development and properties of genetically encoded pH sensors in plants. Front Plant Sci. 2013, 4, 523.

14. Tyssandier, V.; Reboul, E.; Dumas, J.F.; Bougteloup-Demange, C.; Armand, M.; Marcand, J.; Sallas, M.; Borel, P. Processing of vegetable-borne carotenoids in the human stomach and duodenum. Am. J. Physiol.-Gastrointest. Liver Physiol. 2003, 284, G913-G923.

15. Platt, F.M.; Boland, B.; van der Spoel, A.C. The cell biology of disease: Lysosomal storage disorders: The cellular impact of lysosomal dysfunction. J. Cell Biol. 2012, 199, 723-734.

16. Perron, N.R.; Brumaghim, J.L. A review of the antioxidant mechanisms of polyphenol compounds related to iron binding. Cell Biochem. Biophys. 2009, 53, 75-100.

17. Miller, D.M.; Buettner, G.R.; Aust, S.D. Transition metals as catalysts of autoxidation reactions. Free Radic. Biol. Med. 1990, 8, 95-108.

18. Welch, K.D.; Davis, T.Z.; van Eden, M.E.; Aust, S.D. Deleterious iron-mediated oxidation of biomolecules. Free Radic. Biol. Med. 2002, 32, 577-583.

19. De Souza, R.F.V.; de Giovani, W.F. Antioxidant properties of complexes of flavonoids with metal ions. Redox Rep. 2004, 9, 97-104. 
20. Mahal, H.S.; Kapoor, S.; Satpati, A.K.; Mukherjee, T. Radical scavenging and catalytic activity of metal-phenolic complexes. J. Phys. Chem. B 2005, 109, 24197-24202.

21. Bravo, L. Polyphenols: Chemistry, dietary sources, metabolism, and nutritional significance. Nutr. Rev. 1998, 56, 317-333.

22. Dangles, O. Antioxidant activity of plant phenols: Chemical mechanisms and biological significance. Curr. Org. Chem. 2012, 16, 692-714.

23. Giampieri, F.; Alvarez-Suarez, J.; Mazzoni, L.; Forbes-Hernandez, T.; Gasparrini, M.; Gonzàlez-Paramàs, A.; Santos-Buelga, C.; Quiles, J.; Bompadre, S.; Mezzetti, B.; et al. Polyphenol-rich strawberry extract protects puman dermal fibroblasts against hydrogen peroxide oxidative damage and improves mitochondrial functionality. Molecules 2014, 19, 7798-7816.

24. Hallmann, E.; Lipowski, J.; Marszalek, K.; Rembialkowska, E. The seasonal variation in bioactive compounds content in juice from organic and non-organic tomatoes. Plant Food Hum. Nutr. 2013, 68, 171-176.

25. Lo Scalzo, R.; Picchi, V.; Migliori, C.A.; Campanelli, G.; Leteo, F.; Ferrari, V.; di Cesare, L.F. Variations in the phytochemical contents and antioxidant capacity of organically and conventionally grown Italian cauliflower (Brassica oleracea L. subsp. botrytis): Results from a three-year field study. J. Agric. Food Chem. 2013, 61, 10335-10344.

26. Vale, A.P.; Cidade, H.; Pinto, M.; Oliveira, M.B.P.P. Effect of sprouting and light cycle on antioxidant activity of Brassica oleracea varieties. Food Chem. 2014, 165, 379-387.

27. Halliwell, B. Free radicals and antioxidants-quo vadis? Trends Pharmacol. Sci. 2011, 32, 125-130.

28. Benfeito, S.; Oliveira, C.; Soares, P.; Fernandes, C.; Silva, T.; Teixeira, J.; Borges, F. Antioxidant therapy: Still in search of the 'magic bullet'. Mitochondrion 2013, 13, 427-435.

29. Giampieri, F.; Alvarez-Suarez, J.M.; Battino, M. Strawberry and Human Health: Effects beyond Antioxidant Activity. J. Agric. Food Chem. 2014, 62, 3867-3876.

30. Del Rio, D.; Rodriguez-Mateos, A.; Spencer, J.P.; Tognolini, M.; Borges, G.; Crozier, A. Dietary (poly)phenolics in human health: Structures, bioavailability, and evidence of protective effects against chronic diseases. Antioxid. Redox Signal. 2013, 18, 1818-1892.

31. Porciuncula, L.O.; Sallaberry, C.; Mioranzza, S.; Botton, P.H.S.; Rosemberg, D.B. The Janus face of caffeine. Neurochem. Int. 2013, 63, 594-609.

32. Kell, D.B. Towards a unifying, systems biology understanding of large-scale cellular death and destruction caused by poorly liganded iron: Parkinson's, Huntington's, Alzheimer's, prions, bactericides, chemical toxicology and others as examples. Arch. Toxicol. 2010, 84, 825-889.

33. Weinreb, O.; Amit, T.; Mandel, S.; Kupershmidt, L.; Youdim, M.B. Neuroprotective multifunctional iron chelators: From redox-sensitive process to novel therapeutic opportunities. Antioxid. Redox Signal. 2010, 13, 919-949.

34. Endesfelder, S.; Zaak, I.; Weichelt, U.; Buhrer, C.; Schmitz, T. Caffeine protects neuronal cells against injury caused by hyperoxia in the immature brain. Free Radic. Biol. Med. 2014, 67, 221-234.

35. Dato, S.; Crocco, P.; Aquila, P.; de Rango, F.; Bellizzi, D.; Rose, G.; Passarino, G. Exploring the role of genetic variability and lifestyle in oxidative stress response for healthy aging and longevity. Int. J. Mol. Sci. 2013, 14, 16443-16472. 
36. Hu, N.; Yu, J.T.; Tan, L.; Wang, Y.L.; Sun, L. Nutrition and the risk of Alzheimer's disease. Biomed. Res. Int. 2013, 2013, 524820.

37. Kubicova, L.; Hadacek, F.; Chobot, V. Quinolinic Acid: Neurotoxin or oxidative stress modulator? Int. J. Mol. Sci. 2013, 14, 21328-21338.

38. Miura, Y.H.; Tomita, I.; Watanabe, T.; Hirayama, T.; Fukui, S. Active oxygens generation by flavonoids. Biol. Pharm. Bull. 1998, 21, 93-96.

39. Pierre, J.L.; Fontecave, M. Iron and activated oxygen species in biology: The basic chemistry. Biometals 1999, 12, 195-199.

40. Chobot, V.; Hadacek, F. Exploration of pro-oxidant and antioxidant activities of the flavonoid myricetin. Redox Rep. 2011, 16, 242-247.

41. Lemanska, K.; Szymusiak, H.; Tyrakowska, B.; Zielinski, R.; Soffers, A.E.M.F.; Rietjens, I.M.C.M. The influence of $\mathrm{pH}$ on antioxidant properties and the mechanism of antioxidant action of hydroxyflavones. Free Radic. Biol. Med. 2001, 31, 869-881.

42. Prochazkova, D.; Bousova, I.; Wilhelmova, N. Antioxidant and prooxidant properties of flavonoids. Fitoterapia 2011, 82, 513-523.

43. Chobot, V.; Kubicova, L.; Bachmann, G.; Hadacek, F. Versatile redox chemistry complicates antioxidant capacity assessment: Flavonoids as milieu-dependent anti- and pro-oxidants. Int. J. Mol. Sci. 2013, 14, 11830-11841.

44. Rice-Evans, C.A.; Miller, N.J.; Paganga, G. Structure-antioxidant activity relationships of flavonoids and phenolic acids. Free Radic. Biol. Med. 1996, 20, 933-956.

45. Pietta, P.G. Flavonoids as antioxidants. J. Nat. Prod. 2000, 63, 1035-1042.

46. Perron, N.R.; Wang, H.C.; Deguire, S.N.; Jenkins, M.; Lawson, M.; Brumaghim, J.L. Kinetics of iron oxidation upon polyphenol binding. Dalton Trans. 2010, 39, 9982-9987.

47. Mladenka, P.; Macakova, K.; Filipsky, T.; Zatloukalova, L.; Jahodar, L.; Bovicelli, P.; Silvestri, I.P.; Hrdina, R.; Saso, L. In vitro analysis of iron chelating activity of flavonoids. J. Inorg. Biochem. 2011, 105, 693-701.

48. Macáková, K.; Mladěnka, P.; Filipský, T.; Ř́ha, M.; Jahodář, L.; Trejtnar, F.; Bovicelli, P.; Proietti Silvestri, I.; Hrdina, R.; Saso, L. Iron reduction potentiates hydroxyl radical formation only in flavonols. Food Chem. 2012, 135, 2584-2592.

49. Nkhili, E.; Loonis, M.; Mihai, S.; El Hajji, H.; Dangles, O. Reactivity of food phenols with iron and copper ions: Binding, dioxygen activation and oxidation mechanisms. Food Funct. 2014, 5, 1186-1202.

50. Khokhar, S.; Apenten, R.K.O. Iron binding characteristics of phenolic compounds: Some tentative structure-activity relations. Food Chem. 2003, 81, 133-140.

51. Natella, F.; Nardini, M.; di Felice, M.; Scaccini, C. Benzoic and cinnamic acid derivatives as antioxidants: Structure-activity relation. J. Agric. Food Chem. 1999, 47, 1453-1459.

52. Bors, W.; Michel, C.; Stettmaier, K.; Lu, Y.R.; Foo, L.Y. Pulse radiolysis, electron paramagnetic resonance spectroscopy and theoretical calculations of caffeic acid oligomer radicals. Biochim. Biophys. Acta-Gen. Subj. 2003, 1620, 97-107.

53. Li, X.F.; Cai, Z.L.; Katsumura, Y.; Wu, G.Z.; Muroya, Y. Reactions of reducing and oxidizing radicals with caffeic acid: A pulse radiolysis and theoretical study. Radiat. Phys. Chem. 2001, 60, $345-350$. 
54. Andjelkovic, M.; van Camp, J.; de Meulenaer, B.; Depaemelaere, G.; Socaciu, C.; Verloo, M.; Verhe, R. Iron-chelation properties of phenolic acids bearing catechol and galloyl groups. Food Chem. 2006, 98, 23-31.

55. Chvatalova, K.; Slaninova, I.; Brezinova, L.; Slanina, J. Influence of dietary phenolic acids on redox status of iron: Ferrous iron autoxidation and ferric iron reduction. Food Chem. 2008, 106, 650-660.

56. Hynes, M.J.; O’Coinceanainn, W. The kinetics and mechanisms of reactions of iron(III) with caffeic acid, chlorogenic acid, sinapic acid, ferulic acid and naringin. J. Inorg. Biochem. 2004, 98, $1457-1464$.

57. Leon-Carmona, J.R.; Galano, A. Is caffeine a good scavenger of oxygenated free radicals? J. Phys. Chem. B 2011, 115, 4538-4546.

58. Lee, C. Antioxidant ability of caffeine and its metabolites based on the study of oxygen radical absorbing capacity and inhibition of LDL peroxidation. Clin. Chim. Acta 2000, 295, 141-154.

59. Kolayli, S.; Ocak, M.; Kucuk, M.; Abbasoglu, R. Does caffeine bind to metal ions? Food Chem. 2004, 84, 383-388.

60. Ko, K.M.; Yick, P.K.; Poon, M.K. T.; Ip, S.P. Prooxidant and antioxidat effects of Trolox on ferric iron-induced oxidation of erythrocyte membrane lipids. Mol. Cell. Biochem. 1994, 141, $65-70$.

61. Takashima, M.; Horie, M.; Shichiri, M.; Hagihara, Y.; Yoshida, Y.; Niki, E. Assessment of antioxidant capacity for scavenging free radicals in vitro: A rational basis and practical application. Free Radic. Biol. Med. 2012, 52, 1242-1252.

62. Gutteridge, J.M.C. Reactivity of hydroxyl and hydroxyl-like radicals discriminated by release of thiobarbituric acid-reactive material from deoxy sugars, nucleosides and benzoate. Biochem. J. 1984, 224, 761-767.

63. Chen, Q.; Espey, M.G.; Sun, A.Y.; Pooput, C.; Kirk, K.L.; Krishna, M.C.; Khosh, D.S.; Drisko, J.; Levine, M. Pharmacologic doses of ascorbate act as a prooxidant and decrease growth of aggressive tumor xenografts in mice. Proc. Natl. Acad. Sci. USA 2008, 105, 11105-11109.

64. Aruoma, O.I. Deoxyribose assay for detecting hydroxyl radicals. In Oxygen Radicals in Biological Systems, Pt C; Siels, H., Abelson, J., Melvin, S., Eds.; Academic Press Inc.: San Diego, CA, USA, 1994; Volume 233, pp. 57-66.

65. Niki, E. Antioxidant capacity: Which capacity and how to assess it? J. Berry Res. 2011, 1, 169-176.

66. Chobot, V.; Drage, S.; Hadacek, F. Redox properties of 8-quinolinol and implications for its mode of action. Nat. Prod. Commun. 2011, 6, 597-602.

Sample Availability: Samples of the compounds are not available from the authors.

(C) 2014 by the authors; licensee MDPI, Basel, Switzerland. This article is an open access article distributed under the terms and conditions of the Creative Commons Attribution license (http://creativecommons.org/licenses/by/4.0/). 